\title{
JNPH
}

Volume 5 No. 1 (Juli 2017)

(C) The Author(s) 2017

\section{IDENTIFIKASI PLASMODIUM PADA PENDERITA MALARIA DI KOTA BENGKULU TAHUN 2017}

\author{
IDENTIFICATION OF PLASMODIUM IN PATIENTS OF MALARIA IN \\ BENGKULU CITY 2017
}

\author{
MURWATI, THALIA GINA ATIKAH, SUSIWATI \\ POLITEKNIK KESEHATAN KEMENTERIAN KESEHATAN BENGKULU \\ SEKOLAH TINGGI ILMU KESEHATAN DEHASEN BENGKULU
}

\begin{abstract}
ABSTRAK
Latar Belakang : Di wilayah Kota Bengkulu, angka kejadian malaria masih cukup tinggi. Tercatat ditahun 2013 dan 2015 angka kesakitan (Annual Parasite Incidence) per 1000 penduduk masih cukup tinggi.Berdasarkan data Dinas Kesehatan Kota Bengkulu data kesakitan dan kematian malaria pada tahun 2015, terjadi jumlah resiko 351,298 dengan angka kesakitan 0,27. Dengan kasus tertinggi di tahun 2015 terjadi di wilayah kerja puskesmas Anggut Atas dengan 103 kasus malaria, di wilayah kerja puskesmas Jalan Gedang 96 kasus malaria dan di wilayah kerja puskesmas Padang Serai 88 kasus malaria. Tujuan Penelitian:Penelitian ini bertujuan untuk mengetahui jenis plasmodium pada pemeriksaan darah tepi pasien malaria. Metode :Metode penelitian ini adalah deskriptif dengan teknik pengambilan sampel purposive sampling dan dilakukan pemeriksaan laboratorium. Sampel dalam penelitian ini sebanyak 35 responden yang memiliki gejala klinis malaria di tiga puskesmas dengan angka kasus malaria tertinggi dan klinik dalam wilayah puskesmas tersebut. Hasil :Hasil penelitian Identifikasi Jenis Plasmodium yang dominan menginfeksi pada kejadian malaria dikota Bengkulu yaitu plasmodiumvivax $(100 \%)$ dari keseluruhan jumlah sampel. Kesimpulan :Jenis plasmodium yang menginfeksi pada pemeriksaan darah tepi penderita malaria adalah plasmodium vivax. Bagi masyarakat diharapkan menggunakan informasi ini dengan bijak agar jumlah kasus malaria dikota bengkulu berkurang dan malaria dapat tereliminasi di Kota Bengkulu.
\end{abstract}

Kata Kunci :malaria, plasmodium,penderita malaria

\begin{abstract}
Background: In the area of Bengkulu City, the incidence of malaria is still kind of high. Recorded in 2013 and 2015 morbidity (Annual Parasite Incidence) per 1000 residents is still kind of high. Based on Public Health Office Bengkulu city of morbidity data and mortality of malaria in 2015, the number of risks 351,298 with the morbidity of 0.27 . With the highest cases in 2015 occurred in the working area of Anggut Atas Public Health Center with 103 cases of malaria, in the work area of jalan Gedang public health centers were 96 cases of malaria and in the work area of Padang Serai Public Health Center were 88 cases of malaria. Objectives: This study aims to determine the type of plasmodium on the examination of peripheral blood of malaria patients. Method: This research method is descriptive with purposive sampling and doing to examination in the laboratory. Samples in this study were 35 respondents who had clinical symptoms of malaria in three of public health centers with highest malaria cases and
\end{abstract}


clinics in the work area of public health centers. Result: The result of Identification of Plasmodium Type that dominantly infect on malaria incident in Bengkulu city, that is plasmodiumvivax (100\%) from total sample. Conclusion: The type of plasmodium that infects the peripheral blood examination of malaria sufferers is plasmodium vivax. For the people are expected to use this information wisely to reduce the number of malaria cases in the city of bengkulu and malaria can be eliminated in the city of Bengkulu.

Keywords: malaria, plasmodium, malaria patient

\section{PENDAHULUAN}

Penyakit infeksi parasit malaria disebabkan protozoa golongan Plasmodium, yang penularannya bersumber melalui gigitan nyamuk. Nyamuk Anopheles sp membawa parasit Plasmodium sp infektif yang masuk ke dalam tubuh manusia melalui gigitan nyamuk betina. Parasit Plasmodium sp yang ditemukan pada manusia terdiri dari Plasmodium malariae, Plasmodium vivax, Plasmodium falciparum, Plasmodium ovale dan plasmodium paling baru yang ditemukan adalah Plasmodium knowlesi (Arsin, 2012).

Permasalahan kesehatan masyarakat salah satunya malaria. Hal ini dikarenakan penyakit ini dapat mempengaruhi derajat kesehatan masyarakat melalui angka kesakitan dan kematian pada masyarakat akibat malaria. Malaria dapat menyebabkan anemia dan penurunan tingkat produktivitas serta salah satu pembunuh terbesar terutama pada kelompok dengan faktor risiko tinggi misalnya bayi, balita dan ibu hamil (Kementerian Kesehatan, 2011). Penularan penyakit tidak hanya didaerah endemis malaria saja tetapi juga pada daerah tropis dan di dunia (Budiyanto, 2011).

Target yang ditetapkan oleh World Health Assembly dan Kemitraan Roll Back Malaria (RBM) untuk mengurangi jumlah kasus dan kematian akibat malaria yang tercatat sebesar $50 \%$ atau lebih pada akhir tahun 2010 dan sebesar $75 \%$ atau lebih pada tahun 2011 (WHO, 2012). Sebaliknya, selama35 tahun terakhir, kejadian malaria telah meningkat 2-3-kalilipat (Kementerian Kesehatan, 2011). Diagnosis dini yang tepat dan cepat serta terapi yang akurat Merupakan kunci untuk meminimalkan morbiditas dan mortalitas akibat malaria. WHO merekomendasikan manejemen kasus malaria berdasarkan pada parasite-based diagnosis untuk semua kasus. Di Indonesia diagnosis malaria ditegakkan dengan pemeriksaan mikroskopik sediaan darah dan tes diagnosis cepat (Rapid Diagnostic Test-RDT). Penggunaan RDT membantu dalam menegakkan parasite- based diagnosis di daerah dimana kualitas mikroskopik yang baik tidak ada. Namun, penggunaan RDT memiliki kekurangan yaitu tidak dapat membedakan jenis plasmodium yang menginfeksi secara pasti. Sehingga pemberian terapi yang tepat pada penderita akan sulit dilakukan.

Menurut laporan WHO Tahun 2011, malaria lazim di 106 negara didunia tropis dan semi tropik yang merupakan rumah bagi lebih dari setengah penduduk dunia. Pada sebagian besar daerah, malaria merupakan masalah abadi dan perkiraan beban malaria bervariasi. Setiap tahun, malaria dilaporkan lebih dari 250-660 juta infeksi (kasus) dan lebih dari satu juta kematian. Menurut WHO (2014), angka kematian Malaria di dunia pada tahun 2013 masih mencapai 47\% dan 78\% diantaranya ialah anak - anak yang berumur dibawah 5 tahun. Indonesia masih menjadi negara transmisi Malaria atau berisiko Malaria karena pada tahun 2010 terdapat 229.819 kasus positif Malaria dan meningkat menjadi 256.592 kasus pada tahun 2011 (Kemenkes, 2012). Sesuai profil kesehatan Indonesia tahun 2010, terdapat sekitar $80 \%$ kabupaten/kota di Indonesia termasuk kategori endemis Malaria dengan lebih dari $45 \%$ penduduknya berdomisili di desa endemis. Pada tahun 2013, data menunjukkan bahwa terdapat $14 \%$ daerah endemis tinggi 
Malaria dan $71 \%$ daerah endemis rendah Malaria di Indonesia(Kementerian Kesehatan, 2014). Plasmodium penyebab malaria yang ada di Indonesia terdapat beberapa jenis yaitu plasmodium falsifarum, plasmodium vivax, plasmodium malariae, plasmodium ovale dan yang mix atau campuran.

Pada tahun 2009 penyebab malaria yang tertinggi adalah plasmodium vivax $(55,8 \%)$, kemudian plasmodium falsifarum, sedangkan plasmodium ovale tidak dilaporkan. Data ini berbeda dengan data riskesdas 2010, yang mendapatkan $86,4 \%$ penyebab malaria adalah plasmodium falsifarum, dan plasmodium vivax sebanyak $\quad 6,9 \% \quad$ (Kementerian Kesehatan, 2011).

Dari hasil Riskesdas diperoleh point prevalence malaria adalah $0,6 \%$, namun hal ini tidak menggambarkan kondisi malaria secara keseluruhan dalam satu tahun karena setiap wilayah dapat mempunyai masa-masa puncak (pola epidemiologi) kasus yang berbeda-beda. Spesies parasit malaria yang paling banyak ditemukan adalah Plasmodium falciparum $(86,4 \%)$ sedangkan sisanya adalah Plasmodium vivax dan campuran antara $P$. falciparum dan $P$. Vivax. Namun data sebaran parasit perwilayah tidak diperoleh, sehingga tidak dapat diketahui jenis parasit yang dominan per suatu wilayah.

Di wilayah kota Bengkulu, angka kejadian malaria masih cukup tinggi. Tercatat ditahun 2013 dan 2015 angka kesakitan (Annual Parasite Incidence) per 1000 penduduk masih cukup tinggi, walaupun terdapat penurunan angka kesakitan di setiap tahunnya. Berdasarkan data Dinas Kesehatan Kota Bengkulu data kesakitan dan kematian malaria pada tahun 2015, terjadi jumlah resiko 351,298 dengan angka kesakitan 0,27. Dengan kasus tertinggi di tahun 2015 terjadi di wilayah kerja puskesmas Anggut Atas dengan 103 kasus malaria, di wilayah kerja puskesmas Jalan Gedang 96 kasus malaria dan di wilayah kerja puskesmas Padang Serai 88 kasus malaria. Namun jumlah kasus ini tidak tercatat di Dinas Kesehatan setempat. Sebab, data Dinas Kesehatan Kota hanya berdasarkan data puskesmas yang ada di Kota
Bengkulu. Tidak termasuk data Klinik yang terdapat di Kota bengkulu.

\section{TUJUAN PENELITIAN}

Untuk mengetahui distribusi penyebaran malaria dan mengetahui jenis plasmodium pada pemeriksaan darah tepi pasien malaria di kota Bengkulu Tahun 2017.

\section{METODE PENELITIAN}

Penelitian ini merupakan jenis penelitian deskriptif dengan pendekatan laboratorium. Pengambilan sampel yang digunakan yaitu pemeriksaan darah tepi. Pemeriksaan darah tepi dilakukan untuk mengamati ada atau tidak plasmodium beserta jenisnya dalam tubuh. Pemeriksaan darah tepi dilakukan dalam satu waktu. Populasi dalam penelitian ini adalah penderitadengan gejala klinis malaria di tiga puskesmas dengan angka kejadian malaria tinggi dan klinik di wilayah tersebut.

\section{HASIL PENELITIAN}

Hasil analisis penelitian identifikasi plasmodium pada penderita malaria di Kota Bengkulu Tahun 2017 dilakukan pada 35 responden dengan hasil distribusi frekuensi plasmodium yang disajikan pada tabel $1 \mathrm{di}$ bawah ini.

Tabel 1 Distribusi frekuensi plasmodium pada penderita malaria di Kota Bengkulu tahun 2017

\begin{tabular}{c|c|c}
\hline Jenis Plasmodium & Frekuensi & $\%$ \\
\hline Plasmodium Falciparum & 0 & $0 \%$ \\
\hline Plasmodium vivax & 35 & $100 \%$ \\
\hline Plasmodium ovale & 0 & $0 \%$ \\
\hline Plasmodium malariae & 0 & $0 \%$ \\
\hline Jumlah & 35 & $100 \%$ \\
\hline
\end{tabular}

Berdasarkan Tabel 1 Menunjukan hasil distribusi plasmodium yang dominan menginfeksi pada kejadian malaria dikota 
Bengkulu yaitu plasmodiumvivax (100\%) dari keseluruhan jumlah sampel.

\section{PEMBAHASAN}

Identifikasi plasmodium pada penderita malaria di Kota Bengkulu menunjukkan bahwa jenis plasmodium yang paling dominan adalah plasmodium vivaxsebesar $100 \%$. Hal ini dapat dilihat dengan pengamatan sediaan apus darah dimikroskop dengan adanya eritrosit yang terinfeksi plasmodium. Ukuran eritrosit yang terinfeksi Plasmodium jenis vivax biasanya mengalami perbesaran jika dibandingkan dengan ukuran eritrosit normal disekitarnya dan terdapat cincin biru (dari pewarnaan Giemsa) dengan bintik Schuffner (stadium tropozoit) pada eritrosit yang terinfeksi.

Penelitian ini sejalan dengan penelitian yang dilakukan oleh Lukman Hakim dengan judul Malaria : Epidemiologi and Diagnostic pada tahun 2011, yaitu di Indonesia, spesies Plasmodium yang hidup pada manusia yang dominan di seluruh wilayah di Indonesia adalah Plasmodium falciparum dan Plasmodium vivax. Sedangkan Plasmodium ovale dan Plasmodium malariae biasanya ditemukan di wilayah Indonesia bagian Timur. Ini dikarenakan letak geografis Indonesia yang berada di garis kaltulistiwa yang menyebabkan Indonesia beriklim tropis. Indonesia bagian barat dan tengah memiliki suhu yang cukup hangat sehingga memungkinkan jenis Plasmodium falciparum dan Plasmodium vivaxberkembang baik di daerah-daerah yang masuk dalam batas. Sementara di bagian timur Indonesia, suhu udara cukup lembab dan banyaknya pegunungan-pegunungan tinggi yang menyebabkan suhu lebih rendah dibandingkan di bagian tengah dan bagian barat. Dan jenis plasmodium yang membutuhkan cuaca/suhu yang lebih dingin dan lembab, dapat ditemukan disini walaupun dengan jumlah yang sedikit.

Pemeriksaan plasmodium pada penderita malaria di Kota Bengkulu merupakan salah satu teknik diagnosa malaria yang diyakini dan dapat menemukan jenis serta stadium dari parasit plasmodium. Pemeriksaan dilakukan secara mikroskopik dengan melakukan pembacaan sediaan darah malaria. Sediaan darah yang dapat digunakan yaitu sediaan darah tipis dan sediaan darah tebal. Sediaan apus darah tipis membutuhkan volume darah yang relatif sedikit dibandingkan dengan sediaan tetes darah tebal. Apabila pemeriksaan hanya untuk menentukan seseorang terinfeksi plasmodium atau tidak, disarankan menggunakan sediaan darah tebal karena akan lebih cepat menemukan parasit. Sebaliknya jika sediaan digunakan untuk menonjolkan morfologi parasit untuk mengidentifikasai jenisnya, disarankan membuat sediaan apus tipis karena dapat memperlihatkan morfologi plasmodium dengan lebih jelas. (Organization and Control, 2010).

Dalam hal melakukan identifikasi plasmodium, pengetahuan dasar teori sangat diperlukan tetapi bukan menjadi satu satunya penentu keberhasilan identifikasi oleh seorang Analis Kesehatan. Seringkali temuan mikroskop dilapangan sangat berbeda dengan gambaran skematis dari teori yang ada. Secara nyata kita terkadang sulit menemukan morfologi plasmodium yang lengkap sebagaimana teorinya. Plasmodium yang kita lihat secara mikroskopik dalam sediaan darah adalah parasit yang ada pada fase eritrositer siklus aseksual sehingga kemungkinan stadium yang ditemukan adalah stadium tropozoit, schizont atau gametosit. Pada diagnosa malaria, pasien dengan gejala klinis malaria dan adanya plasmodium dalam sediaan darah yang diperiksa secara mikroskopik menunjukkan bahwa pasien tersebut positif menderita malaria.

Hasil penelitian ini menunjukkan pasien yang terdiagnosa malaria, plasmodium yang menginfeksinya adalah plasmodium vivax dengan stadium tropozoit. Hal ini disebabkan ditemukannya eritrosit yang terinfeksi dengan adanya cincin biru dan bintik schuffner di dalam eritrosit yang terinfeksi. Jumlah kasus malaria yang ada dalam rentang waktu lebih kurang dua bulan penelitian sangat sedikit 
jika hanya mengambil tempat di tiga puskesmas. Karena dari sampel yang didapat hanya 2 sampel yang teridentifikasi positif malaria. Hal ini yang menjadi alasan kami berinisiatif mencari kasus malaria di klinik yang ada di kota bengkulu. Kami menemukan sebanyak 33 kasus dari klinik-klinik yang kami datangi. Jumlah kasus terbanyak berada di klinik wilayah teluk segara. Jumlah kasus yang ada dinilai masih cukup banyak, penyebabnya adalah kurangnya kesadaran masyarakat dalam menyikapi malaria itu sendiri. Jika dilihat dari pengetahuan masyarakat tentang malaria cukup mememenuhi, tetapi untuk melakukan tindakan, sikap dan perilaku banyak masyarakat yang menyepelekan sakit malaria dan vektor penyebab malaria. Terbukti dengan gambaran dilapangan masih banyak lingkungan masyarakat yang tidak dijaga dengan baik kebersihannya dan kebiasaan masyarakat juga mempengaruhi angka kejadian malaria di daerah endemis malaria.

\section{KESIMPULAN}

Berdasarkan hasil penelitian dan pembahasan, maka dapat disimpulkan distribusi penyebaran malaria banyak ditemukan didaerah yang berdekatan dengan pantai yang memiliki banyak genangan air karena tanah yang ada merupakan tanah gambut dan rawa. Serta pemukiman padat yang berdekatan dengan pasar sebab didaerah ini banyak genangan air yang terjadi akibat sumbatan sampah dan lingkungan yang kurang terjaga baik. Jenis plasmodium yang banyak ditemukan pada pemeriksaan mikroskopik darah tepi penderita malaria adalah plasmodium vivaxdengan frekuensi $100 \%$ dari jumlah sampel yang didapat di Kota Bengkulu.

\section{SARAN}

Bagi akademis adalah diharapkan dari hasil penelitian ini dapat menambah ilmu dibidang parasitologi, yaitu memperkaya informasi tentang jenis plasmodium pada penderita malaria di Kota Bengkulu Bagi tenaga laboratorium, semoga penelitian ini dapat memberikan informasi sehingga tenaga laboratorium dapat lebih memahami penyebaran plasmodium dan mampu mengidentifikasi jenis plasmodium yang ada pada sediaan darah.

Bagi masyarakat diharapkan dari hasil penelitian ini adalah dapat menambah wawasan tentang malaria dan jenis plasmodium yang menginfeksi sehingga dapat melakukan tindakan, sikap, dan prilaku untuk menekan angka kejadian malaria di Kota Bengkulu

\section{DAFTAR PUSTAKA}

Arsin, A. A. (2012) 'malaria di indonesiab Tinjauan Aspek Epidemiologi’. Masagena Press.

Atikoh, I. N. (2015) 'Faktor yang Berhubungan dengan Kejadian Malaria di Desa Selakambang Kecamatan Kaligondang Kabupaten Purbalingga Tahun 2014'.

Budiyanto, A. (2011) 'Faktor Risiko Yang Berpengaruh Terhadap Kejadian Malaria di Daerah Endemis di Kabupaten Oku', Jurnal Pembangunan Manusia Vol, 5(2).

Chandra, B. (2009) 'Ilmu Kedokteran Pencegahan Komunitas', in. EGC.

Cullen, K. A. (2016) 'Malaria SurveillanceUnited States, 2013', MMWR. Surveillance Summaries, 65.

Ernawati, K., Soesilo, B., Duarsa, A. and Adah, R. (2011) 'Hubungan faktor risiko individu dan lingkungan rumah dengan malaria di Punduh Pedada Kabupaten Pesawaran provinsi Lampung Indonesia 2010', Makara Kesehatan, 15(2), pp. 5157.

Jane, at all (2015) 'The Relationship Between Environmental Factors With Incidence Of Malaria In The Outpatient Of Puskesmas Manganitu Sangihe Archipelago Bidang Minat Epidemiologi Fakultas Kesehatan Masyarakat, Universitas Sam Ratulangi'.

Kemenkes (2012) 'Profil kesehatan Indonesia 
tahun 2011', Kementrian Kesehatan Republik Indonesia. Jakarta.

Kementerian Kesehatan, R. I. (2011) 'Buletin Jendela, Data dan Informasi Kesehatan: Epidemiologi Malaria di Indonesia', Jakarta: Bhakti Husada.

Kementerian Kesehatan, R. I. (2014) 'Riset Kesehatan Dasar', Jakarta: Badan Penelitian dan Pengembangan Kesehatan Departemen Kesehatan Republik Indonesia.

Marcus, B. and Babcock, H. (2009) 'Deadly diseases and epidemics: malaria', Chelsea House, New York.

Mulyono, A., Alfiah, S., Sulistyorini, E. and Negari, K. S. (2013) 'Hubungan Keberadaan Ternak Dan Lokasi Pemeliharaan Ternak Terhadap Kasus Malaria Di Provinsi Ntt (Analisis Lanjut Datariskesdas2007)', Vektora: Jurnal Vektor dan Reservoir Penyakit, 5(2 Okt), pp. 71-74.

Natadisastra, D. and Agoes, R. (2009) 'Parasitologi kedokteran: ditinjau dari organ tubuh yang diserang', Jakarta: $E G C$.

Nisa, H. (2007) 'Epidemiologi Penyakit Menular'. Jakarta: UIN Jakarta Press.

Notoatmodjo, S. (2010) 'Metodologi penelitian kesehatan'. Jakarta: Rineka Cipta.

Organization, W. H. and Control, C. for D. (2010) Basic Malaria Microscopy: Tutor's guide. World Health Organization.

Patterson, G. M. (2014) '2014 AMCA Memorial Lecture Honoree: Founding Mothers: Women, Entomology, and Mosquito Control1', Journal of the American Mosquito Control Association. BioOne, 30(3), pp. 239-245.

Rikesdas (2010) 'Riset Kesehatan Dasar (RISKESDAS) Tahun 2010', pp. 1-111.

WHO (2012) 'Global plan for insecticide resistance management in malaria vectors', World Health Organization press, p. 13.

Yawan, S. F. (2006) 'Analisis Faktor Risiko Kejadian Malaria di Wilayah Kerja
Puskesmas Bosnik Kecamatan Biak Timur Kabupaten Biak-Numfor Papua'. program Pascasarjana UNDIP. 